\title{
BUDESONIDE COMPATIBILITY STUDY WITH EXCIPIENTS FOR PREPARATION OF NANOPARTICLE
}

\author{
ASHWIN KUCHEKAR ${ }^{*}$, JAYESH JATHAR ${ }^{1}$, ASHWINI GAWADE ${ }^{1}$
}

1School of Pharmacy, Dr. Vishwanath Karad, MIT, World Peace University, Paud Road, Kothrud, Pune 411038

Email: ashwin.kuchekar@mitwpu.edu.in

Received: 08 Nov 2020, Revised and Accepted: 10 Jan 2021

\section{ABSTRACT}

Objective: As a condition of acceptance and approval of any pharmaceutical product, stability studies ensuring the durability of the consistency, stability and efficacy of the product during the shelf life are taken into consideration. These studies should be conducted according to the guidelines provided by ICH, WHO and other agencies as intended.

Methods: The aim of this research was to evaluate the stability of the budesonide solution in some solutions and excipients and to further study the production of budesonide nanoparticles. In order to study the Budesonide stability mixture of solvent and polymers were used. To study the effect of temperature and relative humidity on the stability of budesonide preparations, prepared mixtures were stored under Accelerated $\left(40{ }^{\circ} \mathrm{C} \pm 2{ }^{\circ} \mathrm{C} / 75\right.$ percent $\mathrm{RH} \pm 5$ percent $\mathrm{RH})$, Intermediate $\left(30^{\circ} \mathrm{C} \pm 2^{\circ} \mathrm{C} / 65\right.$ percent $\mathrm{RH} \pm 5$ percent $\left.\mathrm{RH}\right)$, Long-term $\left(25^{\circ} \mathrm{C} \pm 2{ }^{\circ} \mathrm{C} / 60\right.$ percent $\mathrm{RH} \pm 5$ percent $\left.\mathrm{RH}\right)$ and at $2-8^{\circ} \mathrm{C}$.

Results: Budesonide showed good compatibility at defined stability conditions in one month. Such type of preformulation compatibility study is necessary in preparation of nanoparticles.

Conclusion: It would be helpful in screening and identifying a suitable solvent, polymer and mixture at a desired concentration.

Keywords: Budesonide, Nanoparticles, Surfactant, Poloxamer, Glycerol Monostearate, Stability, Quality

(C) 2021 The Authors. Published by Innovare Academic Sciences Pvt Ltd. This is an open access article under the CC BY license (https://creativecommons.org/licenses/by/4.0/) DOI: https://dx.doi.org/10.22159/ijcpr.2021v13i2.41553. Journal homepage: https://innovareacademics.in/journals/index.php/ijcpr

\section{INTRODUCTION}

Budesonide is a potent glucocorticosteroid with a strong topical anti-inflammatory activity and low systemic effects, which was commonly used by inhalation for the treatment of asthma. Structurally, budesonide is a 16a, 17a-acetal prepared with nbutyraldehyde by reacting 16a, 17a-dihydroxy steroid (16ahydroxyprednisolone) [1]. Budesonide is a combination of two epimers (22R and 22S) due to the insertion of the alkyl chain at the C22 atom (fig. 1). The two epimers tend to have similar pharmacological effects, but in vitro studies have shown that the anti-inflammatory effects of the R-epimer are two to three times stronger. While budesonide has been widely used in the United States, the European Pharmacopoeia has the only pharmacopeia monograph for budesonide (EP). The EP monograph for budesonide notes that the R: S epimer ratio should be in the range 6049: 4051 . Budesonide is subject to thermal degradation, alkali and acid [2, 3].

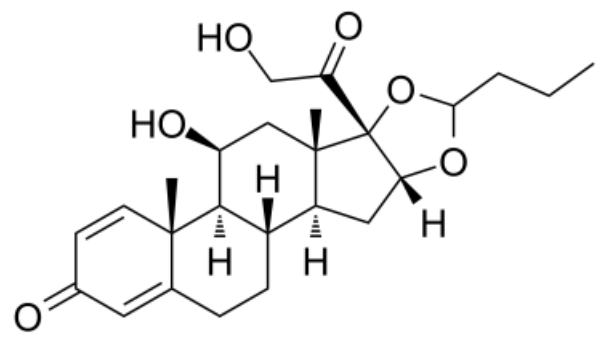

Fig. 1: Structure of budesonide

Large differences between the actual content and the label statements of drug substances have frequently been reported in some mixtures of solvents, excipients and manufactured products [4]. Several other potential variables that could be related to the origin of the materials can be attributed to the low quality of the products $[5,6]$. No published studies have been conducted on the solution stability of solvents and excipients under strictly regulated conditions, as well as on factors that affect stability. In fact, few such experiments have been recorded in the field. Restricted solution phase stability analysis is necessary even for a substance intended to be formulated into dosage forms to ensure that the drug does not degrade in gastrointestinal fluids. This knowledge will allow us to choose the right excipients and solvents to use in budesonide nanoparticles [6-8].

The stability of drugs is influenced not only by their chemistry but also by their climatic conditions, such as room temperature, moisture content, light, etc. is likely to be unstable. However, knowledge about compatibility testing is still very limited. The objective of this article was to evaluate the stability of the budesonide solution in mixture of solvent and polymers and to further study researchers in the production of budesonide nanoparticles.

\section{MATERIALS AND METHODS \\ Materials}

Based on their versatility and physicochemical properties, solvents and excipients have been selected. Glycerol Monostearate (GMS) was obtained from CDH Pvt. Ltd., Mumbai, Poloxamer 188 from BASF, Mumbai and Ethanol from New Neeta Chemicals, Pune.

\section{Methods}

Specific proportions of the different formulations of solvent, water, GMS and Poloxamer 188 were prepared as shown in table 1. In addition, the compatibility study was observed with respect to appearance (coarser particle size, aggregates) at Accelerated (40 $\left.{ }^{\circ} \mathrm{C} \pm 2{ }^{\circ} \mathrm{C} / 75 \% \mathrm{RH} \pm 5 \% \mathrm{RH}\right)$, Intermediate $\left(30{ }^{\circ} \mathrm{C} \pm 2{ }^{\circ} \mathrm{C} / 65 \% \mathrm{RH} \pm 5 \%\right.$ $\mathrm{RH})$, Long term $\left(25^{\circ} \mathrm{C} \pm 2{ }^{\circ} \mathrm{C} / 60 \% \mathrm{RH} \pm 5 \% \mathrm{RH}\right)$ and at $2-8{ }^{\circ} \mathrm{C}$ for $1 \mathrm{mo}$. The effect of relative humidity and temperature on individual components like ethanol, GMS, poloxamer 188 and mixtures was studied. 
Table 1: Varied mixtures for preparation of nanoparticles

\begin{tabular}{ll}
\hline S. No. & Mixtures \\
\hline 1. & Ethanol: Water \\
2. & Ethanol: Water+Budesonide \\
3. & Ethanol: Water+Glycerol Monostearate \\
4. & Ethanol: Water+Poloxamer 188 \\
5. & Ethanol: Water+Budesonide+Glycerol Monostearate \\
6. & Ethanol: Water+Budesonide+Poloxamer 188 \\
7. & Ethabol: Water+Budesonide+Glycerol \\
& Monostearate+Poloxamer 188 \\
\hline
\end{tabular}

\section{RESULTS AND DISCUSSION}

\section{Effect of ethanol}

Budesonide is a crystalline powder insoluble in water, sparingly soluble in aqueous buffers but soluble in organic solvents such as ethanol, dimethyl sulfoxide and dimethylformamide. In ethanol, the observed solubility is respectively 10,20 and $25 \mathrm{mg} / \mathrm{ml}$. A clear solution was observed when a specific amount of budesonide was dissolved in $1 \mathrm{ml}$ of ethanol and $9 \mathrm{ml}$ of water. Ethanol, taking into account glycerol monostearate, poloxamer 188 and water, was therefore used in each mixture $[3,9,10]$.

\section{Effect of poloxamer 188}

Poloxamer 188, a poly (ethylene oxide) (PEO) and poly (propylene oxide) (PPO) triblock copolymer, defends cell membranes against various stresses. Amphiphilic block copolymers are made up of hydrophilic and hydrophobic blocks covalently bonded together [11, 12]. Poloxamers have been used as functional biomaterials for the treatment of cancer, such as drug delivery vectors for heat-sensitive hydrogels and chemosensitizing agents. The stabilizing characteristics of the membrane have been demonstrated in many scenarios by Poloxamer 188 (P188), 8,400 g/mol PEO-PO-PEO triblock copolymer comprising two segments of 75 PEO units on either side of a segment of 30 PPO units [13-15]. Pluronic's is, therefore a new form of nanomedicine that can increase solubility, increase circulation time, and release drugs to target sites. In aqueous medium, it can typically form cylindrical aggregates which exhibit a higher solubilization capacity than the spherical micelles produced by the hydrophilic Pluronic. Pluronic has a well-known colloidal steric stabilizing effect with a high ratio of EO/PO [16-19].

Table 2: Impact on mixtures when kept for accelerated $\left(40{ }^{\circ} \mathrm{C} \pm 2^{\circ} \mathrm{C} / 75\right.$ percent $\mathrm{RH} \pm 5$ percent $\left.\mathrm{RH}\right)$, intermediate $\left(30{ }^{\circ} \mathrm{C} \pm 2{ }^{\circ} \mathrm{C} / 65\right.$ percent $R H \pm 5$ percent $R H)$, long-term $\left(25^{\circ} \mathrm{C} \pm 2{ }^{\circ} \mathrm{C} / 60\right.$ percent $\mathrm{RH} \pm 5$ percent $\left.\mathrm{RH}\right)$ and at $2-8{ }^{\circ} \mathrm{C}$ for one month

\begin{tabular}{|c|c|c|c|c|c|}
\hline S. No. & Mixtures & $\begin{array}{l}30{ }^{\circ} \mathrm{C} \pm 2{ }^{\circ} \mathrm{C} / 65 \% \\
\mathrm{RH} \pm 5 \% \text { RH }\end{array}$ & $\begin{array}{l}40{ }^{\circ} \mathrm{C} \pm 2{ }^{\circ} \mathrm{C} / 75 \% \\
\mathrm{RH} \pm 5 \% \mathrm{RH}\end{array}$ & $\begin{array}{l}25^{\circ} \mathrm{C} \pm 2{ }^{\circ} \mathrm{C} / 60 \% \\
\mathrm{RH} \pm 5 \% \mathrm{RH}\end{array}$ & $2-8{ }^{\circ} \mathrm{C}$ \\
\hline 1. & Ethanol: Water & Clear Solution & Clear Solution & Clear Solution & Clear Solution \\
\hline 2. & Ethanol: Water+Budesonide & Clear Solution & Clear Solution & Clear Solution & $\begin{array}{l}\text { Fine Particle } \\
\text { Observed }\end{array}$ \\
\hline 3. & Ethanol: Water+Glycerol Monostearate & Clear Solution & Fine Particle Observed & $\begin{array}{l}\text { Few particles } \\
\text { observed }\end{array}$ & Clear Solution \\
\hline 4. & Ethanol: Water+Poloxamer 188 & Clear Solution & Clear Solution & Clear Solution & Clear Solution \\
\hline 5. & $\begin{array}{l}\text { Ethanol: Water+Budesonide+Glycerol } \\
\text { Monostearate }\end{array}$ & $\begin{array}{l}\text { Fine Particle } \\
\text { Observed }\end{array}$ & Clear Solution & $\begin{array}{l}\text { Fine Particle } \\
\text { Observed }\end{array}$ & $\begin{array}{l}\text { Fine Particle } \\
\text { Observed }\end{array}$ \\
\hline 6. & Ethanol: Water+Budesonide+Poloxamer 188 & Crystal Growth & Clear Solution & Clear Solution & Clear Solution \\
\hline 7. & $\begin{array}{l}\text { Ethanol: Water+Budesonide+Glycerol } \\
\text { Monostearate+Poloxamer } 188\end{array}$ & Clear Solution & Fine Particle Observed & $\begin{array}{l}\text { Fine Particle } \\
\text { Observed }\end{array}$ & $\begin{array}{l}\text { Fine Particle } \\
\text { Observed }\end{array}$ \\
\hline 8. & $\begin{array}{l}\text { Ethanol: Water+Glycerol } \\
\text { Monostearate+Poloxamer } 188\end{array}$ & Crystal Growth & Clear Solution & Clear Solution & Clear Solution \\
\hline
\end{tabular}

\section{Effect of glycerol monostearate}

As an effective stabilizer, polar and non-polar compounds which can form water-in-oil or oil-in-water emulsions act as a shared solvent. These properties also make it helpful as a dispersing agent for pigments in oils or solids in fats, or as a solvent for phospholipids such as lecithin $[20,21]$. When using glyceryl monostearate in a formulation, the possibility of polymorph formation should be recognized. Dispersible and foamy, the alpha form is useful as an emulsifying or preservative agent. For wax dies, the denser and more stable beta form is suitable. To formulate the SLNs, GMS, a non-polar lipid $\left(\mathrm{C}_{21} \mathrm{H}_{42} \mathrm{O}_{4}\right)$, was used. The goal behind the selection of GMS was its high drug entrapment efficiency, as the presence of high amounts of mono-, di-and triglycerides in GMS allows the drug to solubilize in the lipid fraction, and the less specified mixture [22, 23]. of acylglycerol adds greater reach. For the drug molecules to become entangled. An increase in particle size was caused by an increased volume of GMS. The tendency to fuse at high lipid concentrations can be explained by the fact that the size of nanoparticles strongly depends on the lipid concentration [24,25].

The main knowledge prior to formulation is the solubility of drugs in mixtures of ethanol and water. The concentration of ethanol should be kept as low as possible in pharmaceutical preparations. The time consuming and the expensive experimental process is used to refine the composition of solvent mixtures to dissolve the chosen amount of a drug in a given volume of the solution. The size of the particles is increased in the order of ethanol, isopropanol and acetone by nanoparticles prepared using glycerol monostearate. The effects of the solvent also depend on the type of medication. The miscibility of the solvent and the aqueous phases is a prerequisite for the solvent injection process [26, 27].

\section{Ethanol: water and budesonide}

At room temperature, budesonide has very low solubility in water. With adjustable polarity, water is a solvent. When the water temperature is high, the polarity of the water decreases. To measure polarity, the dielectric constant is used. The polarity of water is reduced from 84 to 45 at $150{ }^{\circ} \mathrm{C}$. Decreasing the polarity allows water to dissolve a number of hydrophobic organic compounds. In order to improve the temperature solubility of water, the solubility of organic compounds in water can be improved by adding organic solvents mixed with the solution. The dielectric constant of the mixture of solvents is decreased by adding organic solvents to the mixture like, ethanol $[4,9,28]$. With the addition of ethanol, the solubility of drugs increased, reached maximum values, and then again decreased in ethanol. The same was found in the combination of ethanol: water and ethanol: water+budesonide forming the fine particles at $2-8^{\circ} \mathrm{C}[3,9,10,29]$.

\section{Ethanol: water+glycerol monostearate}

This showed that there is a level of concentration where the intermolecular interaction between GMS and budesonide effectively occurs. The $\mathrm{pH}$ of the solution led the development of lamellar structures in the mixture, regardless of the ratios between GMS and budesonide. It promoted the formation of crystal-like structures leading to the formation of fine particles [20,23,24]. The same phenomenon might have occurred in this mixture leading to the formation of the fine particles at $40{ }^{\circ} \mathrm{C} \pm 2{ }^{\circ} \mathrm{C} / 75 \% \mathrm{RH} \pm 5 \% \mathrm{RH}$ and 25 ${ }^{\circ} \mathrm{C} \pm 2{ }^{\circ} \mathrm{C} / 60 \% \mathrm{RH} \pm 5 \% \mathrm{RH}$ one-month conditions. 
Ethanol: water+budesonide+glycerol monostearate and ethanol: water+budesonide+glycerol monostearate+poloxamer 188

Clear solution was obtained at $40{ }^{\circ} \mathrm{C} \pm 2{ }^{\circ} \mathrm{C} / 75 \% \mathrm{RH} \pm 5 \% \mathrm{RH}$ for Ethanol: Water+Budesonide+Glycerol Monostearate and at $30{ }^{\circ} \mathrm{C} \pm 2$ ${ }^{\circ} \mathrm{C} / 65 \% \mathrm{RH} \pm 5 \% \quad \mathrm{RH}$ for Ethanol: Water+Budesonide+Glycerol Monostearate+Poloxamer 188. The other conditions exhibited presence of fine particles which can be controlled by varying the concentrations of the surfactant and the solvent used in the formulation. The observed fine particles may be because of a heterogeneous network of crystalline particles was formed by the mixture of GMS, promoting non-uniform bond strength and the resulting "ductile-like" rupture [22]. As the gel is sheared, the system might collapse into smaller clusters of aggregates, but with the reduction in shear, the reestablishment of these clusters into an organized and cohesive network would be hampered as the shear forces have overcome the Brownian motion of suspended crystals [14, 30]. Nanoparticles are affected by the initial amount of drug used. The $\mathrm{pH}$ of the aqueous medium can also be changed by increasing the concentration of the drug, especially when the drugs have $\mathrm{pH}$ dependent groups, and these changes in $\mathrm{pH}$ can lead to precipitation of the drug and increase the PS and PDI. Therefore, as used, drugs generally buffer the aqueous phase to preserve the $\mathrm{pH}$. Additionally, the amount of drug present is generally much smaller than the amount of aqueous phase. In such cases, by increasing the concentration of the drug, the $\mathrm{pH}$ of the aqueous phase will not be significantly changed [31-33]. Due to the increase in free surface energy, aggregation occurs, so that the particles begin to interact with each other, causing changes in the particle size. As a dispersing medium, the use of a surfactant serves as a steric stabilizer and inhibits the incorporation of particles to prevent the formation of aggregates. A change in particle size is caused by the presence of these aggregates [26, 28-30].

\section{Ethanol: water+glycerol monostearate+poloxamer 188}

Crystal growth was observed when kept for $30{ }^{\circ} \mathrm{C} \pm 2{ }^{\circ} \mathrm{C} / 65 \%$ $\mathrm{RH} \pm 5 \% \mathrm{RH}$ whereas a clear solution was obtained in rest of the conditions. This may be observed due to particle aggregation induced by surface-bound surfactants, an increase in surfactant concentration contributes to a higher PDI. This was accompanied by an observation that, as increased drug molecules attempt to build up the system, there is a need for surfactants to stabilize the system [4].

\section{CONCLUSION}

The various mentioned combinations have advantages and disadvantages of its own at a specific concentration. Many factors should be considered when choosing an appropriate mixture prepare nanoparticles for its efficacy, quality and safety. Budesonide in few mixtures showed good compatibility at defined stability conditions in one month. Such type of preformulation compatibility study is necessary in preparation of nanoparticles. It would be helpful in screening and identifying a suitable solvent, polymer and mixture at a desired concentration.

\section{ACKNOWLEDGEMENT}

The authors are grateful to BASF, Mumbai for providing the gift sample of Poloxamer 188.

\section{FUNDING}

Nil

\section{AUTHORS CONTRIBUTIONS}

All the authors have contributed equally.

\section{CONFLICTS OF INTERESTS}

The authors declare that there is no conflict of interests regarding the publication of this manuscript.

\section{REFERENCES}

1. Kuenzig ME, Rezaie A, Seow CH, Otley AR, Steinhart AH, Griffiths AM, et al. Budesonide for maintenance of remission in Crohn's disease. Vol. 2014, Cochrane Database of Systematic Reviews. 2014.
2. O'Byrne PM, FitzGerald JM, Bateman ED, Barnes PJ, Zhong N, Keen C, et al. Inhaled Combined Budesonide-Formoterol as Needed in Mild Asthma. N Engl J Med. 2018;378:1865-76.

3. Ali HSM, York P, Blagden N, Soltanpour S, Acree WE, Jouyban A. Solubility of budesonide, hydrocortisone, and prednisolone in ethanol+water mixtures at $298.2 \mathrm{~K}$. J Chem Eng Data. 2010;55:578-82.

4. Abbasalipourkabir R, Salehzadeh A, Abdullah R. Characterization and stability of nanostructured lipid carriers as drug delivery system. Pakistan J Biol Sci. 2012;15:141-6.

5. Bajaj S, Singla D, Sakhuja N. Stability testing of pharmaceutical products. J Appl Pharm Sci 2012;2:129-38.

6. Blessy M, Patel RD, Prajapati PN, Agrawal YK. Development of forced degradation and stability indicating studies of drugs-a review. J Pharm Anal 2014;4:159-65.

7. Yoshioka S, Stella VJ. Stability of drugs and dosage forms [Internet]. Stability of Drugs and Dosage Forms. Springer, Boston MA; 2002. Available from: https://link.springer.com/ book/10.1007/b114443\#authorsandaffiliationsbook. [Last accessed on 02 Oct 2020].

8. Rajashi B Pharate, Suneela S Dhaneshwar. Stability-indicating high-performance thin-layer chromatography method for simultaneous estimation of formoterol fumarate dihydrate and fluticasone propionate in bulk drug and pharmaceutical dosage form. Asian J Pharm Clin Res 2019;12:149-55.

9. Carr AG, Branch A, Mammucari R, Foster NR. The solubility and solubility modelling of budesonide in pure and modified subcritical water solutions. J Supercrit Fluids 2010;55:37-42.

10. Jouyban A, Acree WE, Martínez F. Preferential solvation of some corticosteroids in \{ethanol +water $\}$ mixtures at $298.2 \mathrm{~K}$. J Mol Liq 2020;312:113249.

11. Shen Y, Lu F, Hou J, Shen Y, Guo S. Incorporation of paclitaxel solid dispersions with poloxamer188 or polyethylene glycol to tune drug release from poly( $\varepsilon$-caprolactone) films. Drug Dev Ind Pharm 2013;39:1187-96.

12. Lin X, Shi Y, Yu SS, Li S, Li W, Li M, et al. Preparation of poloxamer188-b-PCL and study on in vitro radioprotection activity of curcumin-loaded nanoparticles. Front Chem 2020;8:212.

13. Yan F, Zhang C, Zheng Y, Mei L, Tang L, Song C, et al. The effect of poloxamer 188 on nanoparticle morphology, size, cancer cell uptake, and cytotoxicity. Nanomed Nanotechnol Biol Med 2010;6:170-8.

14. Moghimi SM, Hunter AC, Dadswell CM, Savay S, Alving CR, Szebeni J. Causative factors behind poloxamer 188 (Pluronic F68, Flocor ${ }^{\mathrm{TM}}$ )-induced complement activation in human sera. A protective role against poloxamer-mediated complement activation by elevated serum lipoprotein levels. Biochim Biophys Acta Mol Basis Dis 2004;1689:103-13.

15. G Moloughney J, Weisleder N. Poloxamer 188 (P188) as a membrane resealing reagent in biomedical applications. Recent Pat Biotechnol 2013;6:200-11.

16. Tian JL, Zhao YZ, Jin Z, Lu CT, Tang QQ, Xiang Q, et al. Synthesis and characterization of poloxamer 188-grafted heparin copolymer. Drug Dev Ind Pharm 2010;36:832-8.

17. Passerini N, Albertini B, Gonzalez Rodriguez ML, Cavallari C, Rodriguez L. Preparation and characterisation of ibuprofenpoloxamer 188 granules obtained by melt granulation. Eur J Pharm Sci 2002;15:71-8.

18. Gibbs WJ, Hagemann TM. Purified poloxamer 188 for sickle cell vaso-occlusive crisis. Ann Pharmacother 2004;38:320-4.

19. Kim M, Haman KJ, Houang EM, Zhang W, Yannopoulos D, Metzger JM, et al. PEO-PPO diblock copolymers protect myoblasts from hypo-osmotic stress in vitro dependent on copolymer size, composition, and architecture. Biomacromolecules 2017;18:2090-101.

20. Barroso NG, Okuro PK, Ribeiro APB, Cunha RL. Tailoring properties of mixed-component oleogels: wax and monoglyceride interactions towards flaxseed oil structuring. Gels 2020;6:5.

21. Borges A, de Freitas V, Mateus N, Fernandes I, Oliveira J. Solid lipid nanoparticles as carriers of natural phenolic compounds. Antioxidants 2020;9:1-24. 
22. Emami J, Mohiti $\mathrm{H}$, Hamishehkar $\mathrm{H}$, Varshosaz J. Formulation and optimization of solid lipid nanoparticle formulation for pulmonary delivery of budesonide using taguchi and boxbehnken design. Res Pharm Sci 2015;10:17-33.

23. Gardouh A, Ghorab M, Abdel Rahman S. Effect of viscosity, method of preparation and homogenization speed on physical characteristics of solid lipid nanoparticles. ARPN J Sci Technol 2011;2:996-1006.

24. Xia D, Cui F, Gan Y, Mu H, Yang M. Design of lipid matrix particles for fenofibrate: effect of polymorphism of glycerol monostearate on drug incorporation and release. J Pharm Sci 2014;103:697-705.

25. Talele P, Sahu S, Mishra AK. Physicochemical characterization of solid lipid nanoparticles comprised of glycerol monostearate and bile salts. Colloids Surf B 2018;172:517-25.

26. Ortega Toro R, Jimenez A, Talens P, Chiralt A. Effect of the incorporation of surfactants on the physical properties of corn starch films. Food Hydrocoll 2014;38:66-75.

27. Shah M, Pathak K. Development and statistical optimization of solid lipid nanoparticles of simvastatin by using 23 fullfactorial design. AAPS PharmSciTech 2010;11:489-96.
28. Kuchekar AB, Pawar AP. Screening of factors using plackett burman design in the preparation of capecitabine-loaded nano polymeric micelles. Int J Pharm Pharm Sci 2014;6:489-96.

29. Carr AG, Mammucari R, Foster NR. Solubility, solubility modeling, and precipitation of naproxen from subcritical water solutions. Ind Eng Chem Res 2010;49:9385-93.

30. Sondari D, Tursiloadi $S$. The effect of surfactan on formulation and stability of nanoemulsion using extract of Centella Asiatica and Zingiber Officinale. In: AIP Conference Proceedings; 2018.

31. Yuan H, Wang LL, Du YZ, You J, Hu FQ, Zeng S. Preparation and characteristics of nanostructured lipid carriers for controlreleasing progesterone by melt-emulsification. Colloids Surf B 2007;60:174-9.

32. Duong VA, Nguyen TTL, Maeng HJ. Preparation of solid lipid nanoparticles and nanostructured lipid carriers for drug delivery and the effects of preparation parameters of the solvent injection method. Molecules 2020;25:4781.

33. Gawade AR, Boldhane. Solid dosage form development of dabigatran etexilate mesylate with increased solubility and dissolution using co-crystallization. Int J Pharm Sci Res 2020;11:2899-905 